\title{
Synthesis of Polyesters by the Reaction of Dicarboxylic Acids with Alkyl Dihalides Using the DBU Method
}

\author{
Tadatomi NisHIKUBo* and Kazuhiro OzaKI \\ Department of Applied Chemistry, Faculty of Engineering, Kanagawa University, \\ Rokkakubashi, Kanagawa-ku, Yokohama 221, Japan
}

(Received July 6, 1990)

\begin{abstract}
Some polyesters with moderate viscosity were synthesized by reactions of dicarboxylic acids with alkyl dihalides using 1,8-diazabicyclo-[5.4.0]-7-undecene (DBU) in aprotic polar solvents such as dimethylformamide (DMF) and dimethyl sulfoxide (DMSO) under relatively mild conditions. The viscosity and yield of the resulting polymer increased with increasing monomer concentration. Although polymers with relatively high viscosity were obtained when the reaction with $p$-xylylene dichloride was carried out at $70^{\circ} \mathrm{C}$ in DMSO, the viscosity of the resulting polymers decreased with increasing reaction temperature when the reaction with $m$-xylylene dibromide was carried out in DMSO.
\end{abstract}

KEY WORDS Polyester Synthesis / Dicarboxylic Acids / Alkyl Dihalides / DBU Method / Mild Reaction Condition /

Although poly(ethylene terephthalate) is synthesized industrially by transesterification between dimethyl terephthalate and ethylene glycol at relatively high temperatures using certain catalysts, many polyesters are usually prepared by the polycondensation of dicarboxylic-acid chlorides with difunctional alcohols or phenols. These reactions are carried out under relatively mild conditions; however, the activated dicarboxylic-acid chlorides must be prepared and purified before the reaction. Recently, wholly aromatic polyesters have successfully been synthesized by the direct polycondensation of $p$-hydroxybenzoic acid or aromatic dicarboxylic acids with diphenols using condensing reagents such as phenylphosphate esters, ${ }^{1}$ triphenylphosphine-carbon tetrachloride-bases, ${ }^{2}$ triphenylphosphine-hexachloroethane-bases, ${ }^{3}$ triphenylphosphine dichloride-bases, ${ }^{4)}$ diphenyl chlorophosphatebases, ${ }^{5}$ arylsulfonyl chlorides-bases, ${ }^{6}$ or thionyl chloride-bases. ${ }^{7}$ This is a very simple and favorable method for the synthesis of polyesters because the preparation and purification of the activated. dicarboxylic acids is unnecessary.

Some polyesters have also been prepared $^{8}$ by reactions between alkali metal salts of dicarboxylic-acids and aliphatic dibromides using phase transfer catalysis (PTC)s, which is a very convenient method for chemical modification, especially esterification ${ }^{9}$ or etherification, ${ }^{10}$ of polymers containing pandant chloromethyl groups with alkali metal salts of carboxylic acids or phenols under conditions. That is, this PTC method is the reaction between polymeric electrophile and low molecular weight (LMW) nucleophilic reagents. However, the reaction between such pendant nucleophiles as carboxylate or phanol groups in the polymers and LMW electrophilic reagents such as benzyl chlorides or other compounds containing halo-alkyl groups did not proceed quantitatively ${ }^{1,12}$ in the presence

\footnotetext{
* To whom all correspondences should be addressed.
} 
of phase transfer catalysts.

More recently, we found ${ }^{13,14}$ that the reaction of poly(methacrylic acid) or poly(4hydroxystyrene) with alkyl halides such as propargyl bromide and nitrobenzyl bromide proceeded very smoothly under mild conditions using 1,8-diazabicyclo-[5.4.0]-7-undecene (DBU) in aprotic polar solvents such as DMSO and DMF, which is a very convenient and interesting new method for the chemical modification of polymers having pendant carboxylic acid or phenol groups.

In this paper, we wish to report the synthesis of polyesters by the reaction of dicarboxylic acids with aliphatic dihalides using DBU in aprotic polar solvents as a promising new application of DBU method for the polymer synthesis.

\section{EXPERIMENTAL}

Typical Procedure for Model Reaction of Carboxylic Acid with Benzyl Halide Using $D B U$

The reaction was carried out with $3.05 \mathrm{~g}$ $(25 \mathrm{mmol})$ of benzoic acid (BA) and $4.28 \mathrm{~g}$ $(25 \mathrm{mmol})$ of benzyl bromide (BZB) using $3.18 \mathrm{~g}(25 \mathrm{mmol})$ of DBU in $15 \mathrm{ml}$ of DMSO at $30^{\circ} \mathrm{C}$, and yields of benzyl benzoate were determined by GLC.

\section{Typical Procedure for the Reaction of Dicarbox-} ylic Acid with Alkyl Dihalide Using DBU

Isophtalic acid (IPA) $[0.831 \mathrm{~g}(5 \mathrm{mmol})]$ was dissolved in $7 \mathrm{ml}$ of DMSO, and $1.522 \mathrm{~g} \mathrm{(10}$ mmol) of DBU were added with stirring. To the IPA-DBU salt solution, $1.320 \mathrm{~g}(5 \mathrm{mmol})$ of $m$-xylylene dibromide (MXDB) dissolved in $3 \mathrm{ml}$ of DMSO were added. The reaction mixture was stirred at $30^{\circ} \mathrm{C}$ for $3 \mathrm{~h}$, and then poured into $400 \mathrm{ml}$ of methanol. The resulting polymer 3 was purified by reprecipitating twice from tetrahydrofuran (THF) solution into methanol, and finally drying at $60^{\circ} \mathrm{C}$ in vacuo. The yield of polymer 3 was $1.22 \mathrm{~g}(90 \%)$. Inherent viscosity, $0.17\left(0.5 \mathrm{~g} \mathrm{dl}^{-1}\right.$ in DMF at $\left.30^{\circ} \mathrm{C}\right)$. IR (film): $1720(\mathrm{C}=\mathrm{O})$ and $1230 \mathrm{~cm}^{-1}$ (C-O-C). ${ }^{1} \mathrm{H} \mathrm{NMR}\left(\mathrm{CDCl}_{3}\right): 5.4\left(4 \mathrm{H}, \mathrm{s}, \mathrm{CH}_{2}\right)$, $7.3-7.7(5 \mathrm{H}, \mathrm{m}$, aromatic protons), and 8.2 $(2 \mathrm{H}, \mathrm{d}$, aromatic protons), and $8.7 \mathrm{ppm}(1 \mathrm{H}$, $\mathrm{s}$, aromatic protons).

\section{Equipment}

GLC analysis was carried out on a Shimadzu Model GC-9AM gas chromatograph with a $3 \mathrm{~mm} \times 2.6 \mathrm{~m}$ column packed with $3 \%$ Silicon OV-101 on Shimalite W (AW-MDCS). IR spectra were measured on a JASCO model A-202 spectrophotometer. ${ }^{1} \mathrm{H}$ NMR spectra were recorded on a JEOL spectrometer model JNM SP-100 (100 MHz).

\section{RESULTS AND DISCUSSION}

Model reactions of BA or acetic acid (AA) with benzyl chloride (BZC) or BZB were carried out in the presence of some organic bases such as DBU, triethylamine (TEA) or pyridine in DMSO or DMF at $30^{\circ} \mathrm{C}$, and the results are summarized in Table $I$. The reactions of carboxylic acids with benzyl halides proceeded very smoothly to give the corresponding benzyl benzoate (1) and benzyl acetate (2) with quantitative yields using DBU as a base in aprotic polar solvents with short reaction time even at $30^{\circ} \mathrm{C}$. On the other hand, yields of 1 were only 81 and $15 \%$ using TEA and pyridine at $30^{\circ} \mathrm{C}$ for 1 and $6 \mathrm{~h}$, respectively. These results indicate that the reaction of dicarboxylic acid with alkyl dihalide using DBU as a base might be applicable for polyester synthesis.

As summarized in Table II, the reaction of IPA with MXDB was performed with DBU in various aprotic polar solvents. This indicates that DMSO is a suitable solvent to obtain the polyester with high yield and viscosity at $30^{\circ} \mathrm{C}$. Although polymer 3 was prepared in high yield when an equimolecular amount of DBU was used as a base, the polymer was not obtained using other organic bases such as TEA, pyridine, $N, N$-dimethylaminopyridine (DMAP), or a mixture of DBU-pyridine. This 
Synthesis of Polyester by DBU Method

Table I. Synthesis of model compounds by DBU method ${ }^{a}$

\begin{tabular}{|c|c|c|c|c|c|c|}
\hline \multirow{2}{*}{$\begin{array}{l}\text { Run } \\
\text { No. }\end{array}$} & \multirow{2}{*}{$\begin{array}{c}\text { Carboxylic } \\
\text { acid }\end{array}$} & \multirow{2}{*}{$\begin{array}{l}\text { Benzyl } \\
\text { halide }\end{array}$} & \multirow{2}{*}{ Base } & \multirow{2}{*}{$\begin{array}{c}\text { Reaction } \\
\text { solvent }\end{array}$} & \multirow{2}{*}{$\frac{\text { Reaction time }}{\min }$} & \multirow{2}{*}{$\frac{\text { Yield }^{\mathbf{b}}}{\%}$} \\
\hline & & & & & & \\
\hline 1 & BA & BZC & DBU & DMSO & 60 & 86 \\
\hline 2 & BA & BZB & DBU & DMSO & 10 & 100 \\
\hline 3 & AA & BZB & DBU & $\mathrm{DMF}^{\mathrm{c}}$ & 10 & 97 \\
\hline 4 & BA & BZB & TEA & DMSO & 20 & 75 \\
\hline 5 & BA & BZB & TEA & DMSO & 60 & 81 \\
\hline 6 & BA & BZB & Pyridine & DMSO & 10 & 0 \\
\hline 7 & BA & BZB & Pyridine & DMSO & 360 & 15 \\
\hline
\end{tabular}

a The reaction was carried out with $25 \mathrm{mmol}$ of carboxylic acid and $25 \mathrm{mmol}$ of benzyl halide in the presence of $25 \mathrm{mmol}$ of base in $15 \mathrm{ml}$ of solvent at $30^{\circ} \mathrm{C}$.

b Determined by GLC analysis.

c $10 \mathrm{ml}$ of DMF was used.

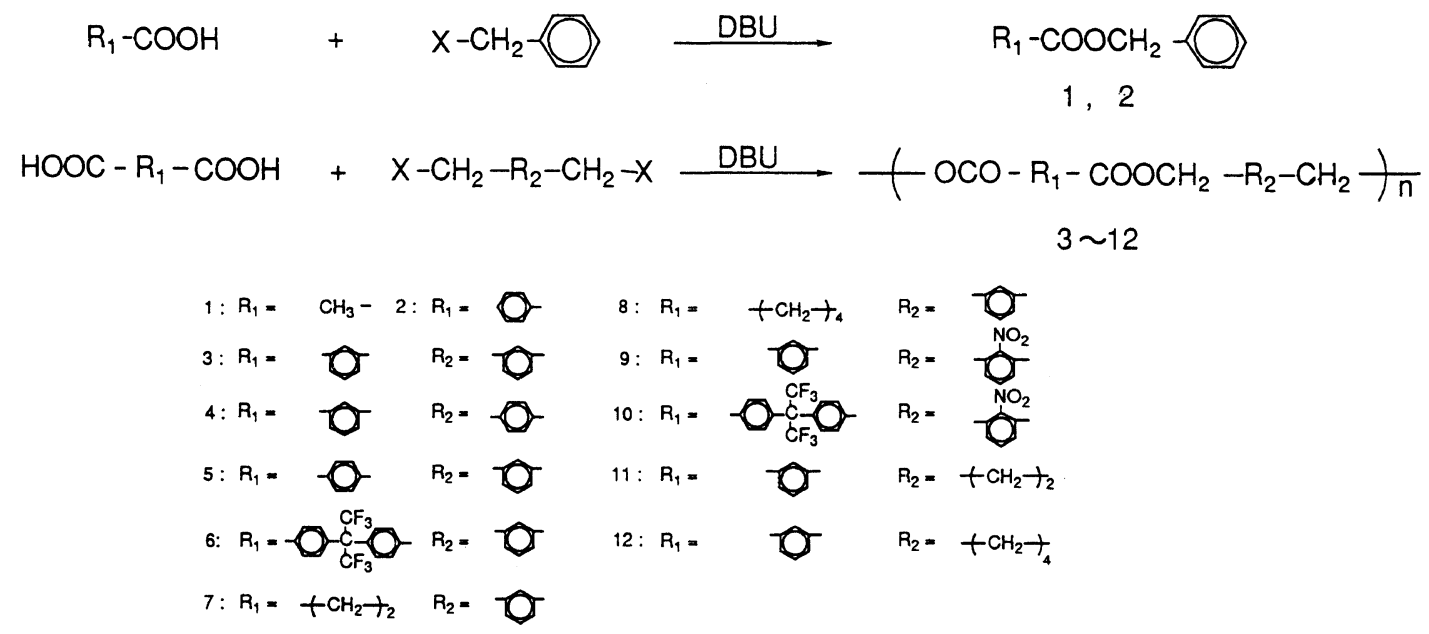

Scheme 1.

means that DBU is an excellent organic base for the synthesis of polyester by the reaction of dicarboxylic acid with alkyl dihalide.

The reaction of IPA with MXDB was conducted in various monomer concentrations at $30^{\circ} \mathrm{C}$ for $3 \mathrm{~h}$. As shown in Figure 1, both yield and inherent viscosity of polymer 3 increased with increasing monomer concentration.

The effect of temperature was examined for the reaction of IPA with MXDB and $p$-xylylene dichloride (PXDC) in DMSO or DMF (Figure 2). Although the viscosity of polymer 3 de- creased with increasing temperature when the reaction with MXDB was carried out in DMSO, the viscosity of polymer 4 increased with increasing temperature on the reaction with PXDC. On the other hand, polymer 3 was obtained with the highest viscosity by reaction with MXDB in DMF at $40^{\circ} \mathrm{C}$. It seems that oxidation of the bromomethyl group ${ }^{15}$ in MXDB also occurs as a side reaction with DMSO-base or with DMF-base, with increasing temperature; because MXDB has higher reactivity than PXDC.

Correlations between viscosities of the re- 
Table II. Reaction of IPA with MXDB using various bases ${ }^{\mathbf{a}}$

\begin{tabular}{|c|c|c|c|c|c|c|}
\hline \multirow{2}{*}{$\begin{array}{l}\text { Run } \\
\text { No. }\end{array}$} & \multicolumn{4}{|c|}{ Reaction condition } & \multirow{2}{*}{$\frac{\text { Yield of polymer }}{\%}$} & \multirow{2}{*}{$\frac{\eta_{\mathrm{sp}} / c^{\mathrm{b}}}{\mathrm{dl} \mathrm{g}^{-1}}$} \\
\hline & Solvent & Base & Temp $/{ }^{\circ} \mathrm{C}$ & Time/h & & \\
\hline 8 & DMF & DBU & 30 & 3 & 80 & 0.15 \\
\hline 9 & DMAc & DBU & 30 & 3 & 85 & 0.11 \\
\hline 10 & NMP & DBU & 30 & 3 & 89 & 0.11 \\
\hline 11 & HMPA & $\mathrm{DBU}$ & 30 & 3 & 91 & 0.13 \\
\hline 12 & DMSO & $\mathrm{DBU}$ & 30 & 3 & 90 & 0.17 \\
\hline 13 & DMSO & Pyridine & 30 & 3 & 0 & \\
\hline 14 & DMSO & $\mathrm{TEA}^{\mathrm{c}}$ & 30 & 3 & 0 & \\
\hline 15 & DMSO & TEA $^{\mathrm{c}}$ & 60 & 24 & 0 & \\
\hline 16 & DMSO & DMAPd & 30 & 3 & 0 & \\
\hline 17 & DMSO & DBU/Pyridine $e^{\mathfrak{e}}$ & 30 & 24 & 0 & \\
\hline
\end{tabular}

a The reaction was carried out with $5 \mathrm{mmol}$ of IPA and $5 \mathrm{mmol}$ of MXDB using $10 \mathrm{mmol}$ of base in $10 \mathrm{ml}$ of solvent.

b Measured at $0.5 \mathrm{~g} \mathrm{dl}^{-1}$ in DMF at $30^{\circ} \mathrm{C}$.

c Triethylamine.

d $N, N$-dimethylaminopyridine.

e $5 \mathrm{mmol}$ of DBU and $5 \mathrm{mmol}$ of pyridine were used.

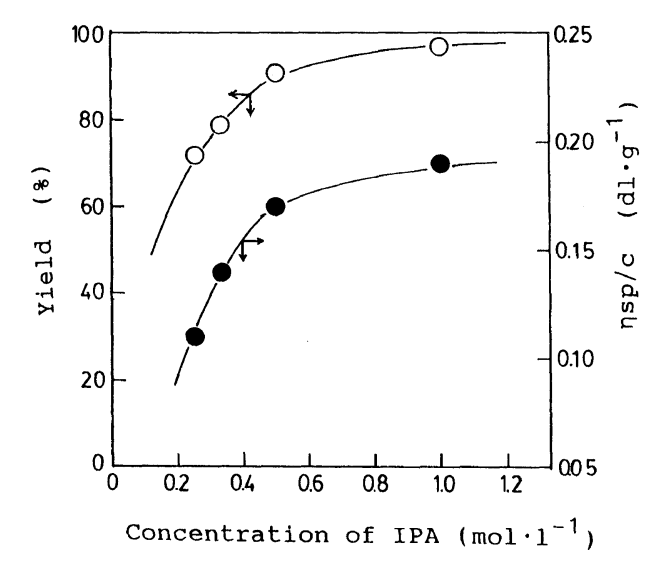

Figure 1. Effect of monomer concentration on the reaction of IPA with MXDB at $30^{\circ} \mathrm{C}$ for $3 \mathrm{~h}$.

sulting polymer and reaction times are shown in Figure 3. The polymers with higher viscosities were obtained after $3 \mathrm{~h}$, and then the viscosity of the resulting polymer depressed gradually with time, when the reaction of IPA with MXDB was carried out in the presence of DBU in DMSO and DMF at $30^{\circ} \mathrm{C}$, respectively. However, we could not be pointed out the causes of decrease of the viscosity from the data.

The viscosity of obtained polymer 4 was

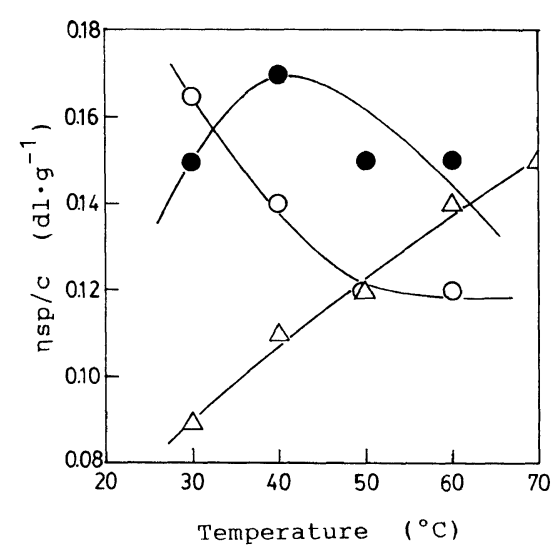

Figure 2. Effect of temperature on the reaction of IPA with MXDB and PXDC for $3 \mathrm{~h}$ : $(\mathrm{O})$, with MXDB in DMSO $(10 \mathrm{ml})$; $(\bigcirc)$, with MXDB in DMF $(10 \mathrm{ml}) ;(\triangle)$, with PXDC in DMSO (12 ml).

almost saturated at $6 \mathrm{~h}$, after which the viscosity increased strongly, when the reaction was performed with PXDC in DMSO at $60^{\circ} \mathrm{C}$. This means that the reactivity of PXDC was lower than MXDB, although polymers 3 and 4 with moderate viscosity could be prepared by either reaction of IPA with MXDB or PXDC using DBU under mild conditions.

The effect of volume of DBU was examined 
to determined reaction conditions (Table III). Polymer 3 with the highest yield and viscosity was obtained using an equimolecular amount of DBU, and the yield and viscosity of the resulting polymer decreased with increasing molar ratio of DBU to the carboxylic acid when

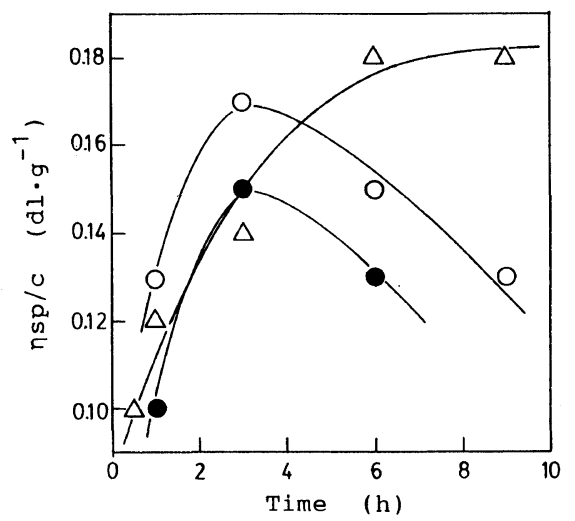

Figure 3. Effect of time on the reaction of IPA with MXDB and PXDC: (O), with MXDB in DMSO (10m l) at $30^{\circ} \mathrm{C} ;(\bigcirc)$, with MXDB in DMF $(10 \mathrm{ml})$ at $30^{\circ} \mathrm{C} ;(\triangle)$, with PXDC in DMSO $(12 \mathrm{ml})$ at $60^{\circ} \mathrm{C}$. the reaction was carried out in DMSO at $30^{\circ} \mathrm{C}$ for $3 \mathrm{~h}$. This means that excess DBU reacted with MXDB to give the corresponding quaternary ammonium salt, and both the yield and the viscosity of the resulting polymer fell dramatically on the addition of excess DBU.

The reactions of some dicarboxylic acids such as IPA, terephthalic acid (TPA), 2,2-bis-

Table III. Effect of the amount of DBU on the reaction of IPA with MXDB ${ }^{\mathrm{a}}$

\begin{tabular}{|c|c|c|c|}
\hline \multirow{2}{*}{$\begin{array}{l}\text { Run } \\
\text { No. }\end{array}$} & Molar ratio of & $\begin{array}{l}\text { Yield of } \\
\text { polymer }\end{array}$ & $\eta_{\mathrm{sp}} / c^{\mathrm{b}}$ \\
\hline & $\mathrm{DBU} /-\mathrm{COOH}$ & $\%$ & $\mathrm{dlg}^{-1}$ \\
\hline 12 & 1.00 & 90 & 0.17 \\
\hline 18 & 1.01 & 88 & 0.14 \\
\hline 19 & 1.10 & 48 & 0.09 \\
\hline 20 & 1.30 & 8 & - \\
\hline
\end{tabular}

a The reaction was carried out with $5 \mathrm{mmol}$ of IPA and $5 \mathrm{mmol}$ of MXDB in $10 \mathrm{ml}$ of DMSO at $30^{\circ} \mathrm{C}$ for $3 \mathrm{~h}$.

b Measured at $0.5 \mathrm{~g} \mathrm{dl}^{-1}$ in $\mathrm{DMF}$ at $30^{\circ} \mathrm{C}$.

Table IV. Reactions of various dicarboxylic acids with alkyl dihalides using DBU method ${ }^{\mathrm{a}}$

\begin{tabular}{|c|c|c|c|c|c|c|c|}
\hline \multirow{2}{*}{$\begin{array}{l}\text { Run } \\
\text { No. }\end{array}$} & \multirow{2}{*}{$\begin{array}{c}\text { Polym. } \\
\text { No. }\end{array}$} & \multirow{2}{*}{$\begin{array}{l}\text { Dicarboxylic } \\
\text { acid }\end{array}$} & \multirow{2}{*}{$\begin{array}{c}\text { Alkyl } \\
\text { dihalide }\end{array}$} & \multicolumn{2}{|c|}{ Reaction condition } & \multirow{2}{*}{$\frac{\text { Yield of polymer }}{\%}$} & \multirow{2}{*}{$\frac{\eta_{\mathrm{sp}} / c^{\mathrm{b}}}{\mathrm{dl} \mathrm{g}^{-1}}$} \\
\hline & & & & Temp $/{ }^{\circ} \mathrm{C}$ & Time/h & & \\
\hline 21 & 3 & IPA & $\mathrm{MXDB}^{\mathrm{c}}$ & 30 & 3 & 97 & 0.19 \\
\hline 22 & 4 & IPA & PXDC & 60 & 6 & 90 & $0.18^{\mathrm{d}}$ \\
\hline 23 & 5 & TPA & MXDB & 30 & 3 & 86 & $0.21^{\mathrm{e}}$ \\
\hline 24 & 6 & ВСРP & MXDB & 30 & 3 & 95 & 0.18 \\
\hline 25 & 7 & SCA & MXDB & 30 & 3 & 60 & $0.13^{d}$ \\
\hline 26 & 8 & APA & MXDB & 30 & 3 & 65 & 0.15 \\
\hline 27 & 3 & IPA & MXDC & 60 & 6 & 84 & 0.12 \\
\hline 28 & 9 & IPA & BMNB $^{f}$ & 30 & 3 & 94 & $0.20^{d}$ \\
\hline 29 & 10 & BCPP & $\mathrm{BMNB}^{\mathrm{f}}$ & 30 & 3 & 94 & 0.22 \\
\hline 30 & 11 & IPA & DBE & 60 & 3 & 66 & $0.08^{d}$ \\
\hline 31 & 12 & IPA & DCB & 60 & 3 & 25 & $0.08^{g}$ \\
\hline 32 & 12 & IPA & DBB & 60 & 3 & 65 & $0.09^{\mathrm{g}}$ \\
\hline 33 & 12 & IPA & DIB & 60 & 3 & 76 & $0.22^{\mathrm{g}}$ \\
\hline
\end{tabular}

a The reaction was carried out with $5 \mathrm{mmol}$ of dicarboxylic acid and $5 \mathrm{mmol}$ of alkyl dihalide using $10 \mathrm{mmol}$ of DBU in $10 \mathrm{ml}$ of solvent.

b Measured at $0.5 \mathrm{~g} \mathrm{dl}^{-1}$ in DMF at $30^{\circ} \mathrm{C}$.

c $5 \mathrm{ml}$ of DMSO was used.

d Measured at $0.5 \mathrm{~g} \mathrm{dl}^{-1}$ in NMP at $30^{\circ} \mathrm{C}$.

e Measured at $0.5 \mathrm{~g} \mathrm{dl}^{-1}$ in chloroform at $30^{\circ} \mathrm{C}$.

f $12 \mathrm{ml}$ of DMSO was used.

${ }^{\mathrm{g}}$ Measured at $0.5 \mathrm{~g} \mathrm{dl}^{-1}$ in $\mathrm{m}$-creasole at $30^{\circ} \mathrm{C}$. 
Table V. IR and ${ }^{1} \mathrm{H}$ NMR spectra of polyesters

\begin{tabular}{|c|c|c|}
\hline $\begin{array}{l}\text { Polym. } \\
\text { No. }\end{array}$ & $\frac{\mathrm{IR}^{\mathrm{a}}}{\mathrm{cm}^{-1}}$ & $\frac{{ }^{1} \mathrm{H} \mathrm{NMR}^{\mathrm{b}}}{\mathrm{ppm}}$ \\
\hline 3 & $\begin{array}{l}1720(\mathrm{C}=\mathrm{O}) \\
1230(\mathrm{C}-\mathrm{O}-\mathrm{C})\end{array}$ & $\begin{array}{l}5.4\left(4 \mathrm{H}, \mathrm{s}, \mathrm{CH}_{2}-\mathrm{O}\right), 7.3-7.7(5 \mathrm{H}, \mathrm{m}, \mathrm{Ar}-\mathrm{H}) \\
8.2(2 \mathrm{H}, \mathrm{d}, \mathrm{Ar}-\mathrm{H}), 8.7(1 \mathrm{H}, \mathrm{s}, \mathrm{Ar}-\mathrm{H}) .\end{array}$ \\
\hline 4 & $\begin{array}{l}1730(\mathrm{C}=\mathrm{O}) \\
1270(\mathrm{C}-\mathrm{O}-\mathrm{C})\end{array}$ & $\begin{array}{l}5.3\left(4 \mathrm{H}, \mathrm{s}, \mathrm{CH}_{2}-\mathrm{O}\right), 7.3-7.6(5 \mathrm{H}, \mathrm{m}, \mathrm{Ar}-\mathrm{H}), \\
8.1(2 \mathrm{H}, \mathrm{d}, \mathrm{Ar}-\mathrm{H}), 8.7(1 \mathrm{H}, \mathrm{s}, \mathrm{Ar}-\mathrm{H}) .\end{array}$ \\
\hline 5 & $\begin{array}{l}1720(\mathrm{C}=\mathrm{O}) \\
1270(\mathrm{C}-\mathrm{O}-\mathrm{C})\end{array}$ & $\begin{array}{l}5.4\left(4 \mathrm{H}, \mathrm{s}, \mathrm{CH}_{2}-\mathrm{O}\right), 7.2-7.6(4 \mathrm{H}, \mathrm{m}, \mathrm{Ar}-\mathrm{H}) \\
8.1(4 \mathrm{H}, \mathrm{s}, \mathrm{Ar}-\mathrm{H})\end{array}$ \\
\hline 6 & $\begin{array}{l}1730(\mathrm{C}=\mathrm{O}) \\
1290(\mathrm{C}-\mathrm{O}-\mathrm{C})\end{array}$ & $\begin{array}{l}5.4\left(4 \mathrm{H}, \mathrm{s}, \mathrm{CH}_{2}-\mathrm{O}\right), 7.2-7.6(8 \mathrm{H}, \mathrm{m}, \mathrm{Ar}-\mathrm{H}) \\
8.0-8.3(4 \mathrm{H}, \mathrm{m}, \mathrm{Ar}-\mathrm{H})\end{array}$ \\
\hline 7 & $\begin{array}{l}1740(\mathrm{C}=\mathrm{O}) \\
1170(\mathrm{C}-\mathrm{O}-\mathrm{C})\end{array}$ & $\begin{array}{l}2.7\left(4 \mathrm{H}, \mathrm{m}, \mathrm{CH}_{2}-\mathrm{CO}\right), 5.1\left(4 \mathrm{H}, \mathrm{s}, \mathrm{CH}_{2}-\mathrm{O}\right) \\
7.2(4 \mathrm{H}, \mathrm{s}, \mathrm{Ar}-\mathrm{H})\end{array}$ \\
\hline 8 & $\begin{array}{l}1740(\mathrm{C}=\mathrm{O}) \\
1180(\mathrm{C}-\mathrm{O}-\mathrm{C})\end{array}$ & $\begin{array}{l}1.5-1.9\left(4 \mathrm{H}, \mathrm{br}, \mathrm{CH}_{2}\right), 2.0-2.6\left(4 \mathrm{H}, \mathrm{br}, \mathrm{CH}_{2}-\mathrm{CO}\right) \text {, } \\
5.1\left(4 \mathrm{H}, \mathrm{s}, \mathrm{CH}_{2}-\mathrm{O}\right), 7.2(4 \mathrm{H}, \mathrm{s}, \mathrm{Ar}-\mathrm{H}) .\end{array}$ \\
\hline 9 & $\begin{array}{l}1730(\mathrm{C}=\mathrm{O}) \\
1220(\mathrm{C}-\mathrm{O}-\mathrm{C})\end{array}$ & -c \\
\hline 10 & $\begin{array}{l}1730(\mathrm{C}=\mathrm{O}) \\
1270(\mathrm{C}-\mathrm{O}-\mathrm{C})\end{array}$ & $\begin{array}{l}5.5\left(4 \mathrm{H}, \mathrm{s}, \mathrm{CH}_{2}-\mathrm{O}\right) \\
7.3-7.8,7.9-8.2(11 \mathrm{H}, \mathrm{m}, \mathrm{Ar}-\mathrm{H}) .\end{array}$ \\
\hline 11 & $\begin{array}{l}1720(\mathrm{C}=\mathrm{O}) \\
1220(\mathrm{C}-\mathrm{O}-\mathrm{C})\end{array}$ & -c \\
\hline 12 & $\begin{array}{l}1730(\mathrm{C}=\mathrm{O}) \\
1240(\mathrm{C}-\mathrm{O}-\mathrm{C})\end{array}$ & $\begin{array}{l}1.6-2.3\left(4 \mathrm{H}, \mathrm{br}, \mathrm{CH}_{2}\right), 4.1-4.7\left(4 \mathrm{H}, \mathrm{br}, \mathrm{CH}_{2}-\mathrm{CO}\right) \text {, } \\
7.2-7.7,7.9-8.4,8.5-8.8(4 \mathrm{H}, \mathrm{m}, \mathrm{Ar}-\mathrm{H}) .\end{array}$ \\
\hline
\end{tabular}

a Measured on KRS plate.

b Measured in $\mathrm{CDCl}_{3}$.

c Insoluble in $\mathrm{CDCl}_{3}$ and DMSO- $d_{6}$ at room temperature.

(4-carboxylphenyl)-1,1,1,3,3,3-hexafluoropropane (BCPP), succinic acid (SCA), and adipic acid (APA) with alkyl halides such as MXDB, PXDC, 2,6-dibromomethylnitrobenzene (BMNB), 1,2-dibromoethane (DBE), 1,4dichlorobutane (DCB), 1,4-dibromobutane (DBB), and 1,4-diiodobutane (DIB) were performed to give the corresponding polyesters in DMSO under suitable conditions, which were determined from the above reaction conditions as summarized in Tables II and III, and Figures 1-3.

Polymer 4 was obtained with high yield and viscosity by the reaction of PXDC with IPA at $60^{\circ} \mathrm{C}$ after $6 \mathrm{~h}$ as well as by the reaction of MXDB with IPA, which produced polymer 3 , at $30^{\circ} \mathrm{C}$ for $3 \mathrm{~h}$. Polymer 5 prepared with relatively high viscosity by the reaction of TPA with MXDB was soluble in chloroform, but insoluble in DMF and DMSO. Polymers 6-8 with viscosities $0.13-0.18$ were prepared by the reaction of MXDB with BCPP, SCA, and APA in DMSO at $30^{\circ} \mathrm{C}$ for $3 \mathrm{~h}$. Polymers 9, 10, which can be used as positive type photo-resists, with relatively high viscosity were obtained in high yield by reactions of IPA and $\mathrm{BCPP}$ with $\mathrm{BMNB}$ at $30^{\circ} \mathrm{C}$ after $3 \mathrm{~h}$. It seems that the high reactivity of $\mathrm{BMNB}$ gives polymers with high viscosity under mild conditions. Although the reaction of IPA with DBE produced polymer 11 at $60^{\circ} \mathrm{C}$ after $3 \mathrm{~h}$, the yield and viscosity of the resulting polymer were low. Polymer 12 with higher yield and viscosity was obtained by the reaction of IPA with DIB than with reactions of IPA with DCB and $\mathrm{DBB}$ at $60^{\circ} \mathrm{C}$ for $3 \mathrm{~h}$. This indicates that the reactivity of DIB was higher than that of DCB or DBB. The IR and ${ }^{1} \mathrm{H}$ NMR spectra of polymers 3-12 are summarized in Table $\mathrm{V}$.

The solubilities of the polymers are summa- 
Synthesis of Polyester by DBU Method

Table VI. Solubility of the polyesters ${ }^{\mathrm{a}}$

\begin{tabular}{|c|c|c|c|c|c|c|c|c|c|c|}
\hline \multirow{2}{*}{ Solvent } & \multicolumn{10}{|c|}{ Polymer No. } \\
\hline & 3 & 4 & 5 & 6 & 7 & 8 & 9 & 10 & 11 & 12 \\
\hline Cyclohexane & - & - & - & - & - & - & - & - & - & - \\
\hline Methanol & - & - & - & - & - & - & - & - & - & - \\
\hline Acetone & +- & - & - & +- & - & - & - & ++ & - & - \\
\hline Acetonitril & +- & - & - & +- & + & - & - & +- & - & - \\
\hline Dichloromethane & ++ & ++ & ++ & ++ & ++ & ++ & - & ++ & +- & ++ \\
\hline Chloroform & ++ & ++ & ++ & ++ & ++ & ++ & - & ++ & + & ++ \\
\hline Carbon tetrachloride & + & - & - & +- & ++ & - & - & +- & - & - \\
\hline Toluene & +- & - & - & ++ & - & + & - & ++ & - & - \\
\hline Nitrobenzene & ++ & + & + & ++ & + & ++ & + & ++ & + & + \\
\hline Ethyl acetate & +- & - & - & ++ & - & - & - & ++ & - & - \\
\hline Dioxane & ++ & + & + & ++ & + & ++ & - & ++ & + & - \\
\hline THF & ++ & +- & + & ++ & - & ++ & + & ++ & - & - \\
\hline DMF & ++ & + & + & ++ & ++ & ++ & + & ++ & + & + \\
\hline DMAc & ++ & + & + & ++ & + & ++ & + & ++ & + & + \\
\hline NMP & ++ & ++ & + & ++ & ++ & ++ & ++ & ++ & ++ & + \\
\hline DMSO & + & + & - & +- & + & + & - & + & + & - \\
\hline HMPA & ++ & ++ & - & ++ & + & ++ & ++ & ++ & ++ & + \\
\hline
\end{tabular}

a ++ , soluble at room temperature; + , soluble by heating; +- , partially soluble or swelling; - , insoluble.

rized in Table VI. The data indicate that the solubility of the resulting polyesters vary appreciably depending on the configuration of the polymer skeleton. That is, Polyester (3) derived from isophthalate has higher solubility than polyester (5) from terephthalate. The solubility of polyester (3) obtained from $m$-xylylene dihalide was better than that of polyester (4) from $p$-xylylene dihalide. Although introduction of BCPP moiety having fluoroalkyl group in the polymer skeleton (6, 10) increased the solubility, the introduction of nitrobenzyl moiety in the polymer (9) strongly decreased the solubility.

From these results, it is concluded that certain polyesters with moderate viscosity can be synthesized in high yields by reactions of dicarboxylic acids with alkyl dihalides using equivalent amounts of DBU as an organic base under mild reaction conditions.

\section{REFERENCES}

1. F. Higashi, K. Kubota, M. Sekizuka, Makromal.
Chem., Rapid Commun., 1, 457 (1980).

2. F. Higashi and T. Murakami, Makromol. Chem., Rapid Commun., 2, 273 (1981).

3. N. Ogata, K. Sanui, and H. Itaya, Polym. J., 22, 85 (1990).

4. S. Kitayama, K. Sanui, and N. Ogata, J. Polym. Sci., Polym. Chem. Ed., 22, 2705 (1984).

5. a) F. Higashi, A. Hoshino, and J. Kiyoshige, J. Polym. Sci., Polym. Chem. Ed., 21, 3241 (1983); b) F. Higashi, Y. Yamada, and A. Hoshio, J. Polym. Sci., Polym. Chem. Ed., 22, 2181 (1984); c) F. Higashi, A. Hoshio, Y. Yamada, and M. Ozawa, J. Polym. Sci., Polym. Chem. Ed., 23, 69 (1985).

6. a) F. Higashi, N. Akiyama, and T. Koyama, J. Polym. Sci., Polym. Chem. Ed., 21, 3233 (1983); b) F. Higashi, N. Akiyama, I. Takahashi, and T. Koyama, J. Polym. Sci., Polym. Chem. Ed., 22, 1653 (1984); c) F. Higashi, T. Mashimo, I. Takahashi, and N. Akiyama, $J$. Polym. Sci., Polym. Chem. Ed., 23, 3095 (1985).

7. a) F. Higashi, T. Mashimo, and I. Takahashi, $J$. Polym. Sci., Polym. Chem. Ed., 24, 97 (1986); b) F. Higashi, S. Sugimori, and T. Mashimo, J. Polym. Sci., Polym. Chem. Ed., 26, 1277 (1988).

8. a) M. Ueda, N. Sakai, and Y. Imai, Kobunshi Ronbunshu, 38, 443 (1981); b) G. G. Cameron and K. S. Law, Polymer, 22, 272 (1981); c) G. C. East and M. Morshed, Polymer, 23, 168 (1982).

9. T. Nishikubo, T. Iizawa, K. Kobayashi, Y. Masuda, and M. Okawara, macromolecules, 16, 722 (1983).

10. T. Iizawa, T. Nishikubo, $\mathrm{Y}$. Masuda, and $\mathbf{M}$. 


\section{T. Nishikubo and K. Ozaki}

Okawara, Macromolecules, 17, 982 (1984).

11. T. Shimokawa and T. Noshikubo, Kobunshi Ronbunshu, 43, 901 (1986).

12. S. H. Chen and Y. F. Maa, Macromolecules, 21, 904 (1988).

13. T. Shimokawa and T. Nishikubo, Kobunshi Ronbun- shu, 44, 641 (1987).

14. T. Nishikubo, T. Iizawa, A. Takahashi, and T. Shimokawa, J. Polym. Sci., Polym. Chem. Ed., 28, 105 (1990).

15. J. A. Moore and J. J. Kennedy, J. Macromol. Sci.-Chem., A13, 461 (1979). 